\title{
lon-doping as a strategy to modulate hydroxyapatite nanoparticle internalization
}

\begin{abstract}
Z. Zhao ${ }^{a, b \neq}$, M. Espanol ${ }^{a, b, f,{ }^{*}}$, J. Guillem-Marti, ${ }^{a, b}$, D. Kempf ${ }^{a}$, A. Diez-Escudero ${ }^{a, b}$ and M.-P. Ginebra ${ }^{a, b}$
Although it is widely acknowledged that ionic substitutions on bulk hydroxyapatite substrates have a strong impact on their biological performance, little is known of their effect on nanoparticles (NPs) especially when used for gene transfection or drug delivery. The fact that NPs would be internalized poses many questions but also opens up many new possibilities. The objective of the present work is to synthesize and assess the effect of a series of hydroxyapatite-like (HA) NPs doped with various ions on cell behavior, i.e. carbonate, magnesium and co-addition. We synthesized NPs under similar conditions to allow comparison of results and different aspects in addition to assessing the effect of the doping ion(s) were investigated: 1 ) the effect of performing the cell culture study on citrate-dispersed NPs and on agglomerated NPs, 2) the effect of adding/excluding $10 \%$ of foetal bovine serum (FBS) in the cell culture media and 3 ) the type of cell, i.e. MG-63 versus rat mesenchymal stem cells (rMSCs). The results clearly demonstrated that Mg-doping had a major effect on MG63 cells with high cytotoxicity but not to rMSCs. This was a very important finding because it proved that doping could be a tool to modify NP internalization. The results also suggest that NP surface charge had large impact on MG63 cells and prevents their internalization if it is too negative-this effect was less critical for rMSCs.
\end{abstract}

\section{Introduction}

Hydroxyapatite (HA) based materials have long been considered as potential candidates in the repair, regeneration and substitution of bone tissue owing to their similarity in composition to the mineral phase of bone. There has been a long trajectory since HA began to be used and this material is still now the focus of extensive research [1]. In addition to the use of $\mathrm{HA}$ as a bulk material in bone regeneration applications, HA in the form of nanoparticles (NPs) is a potential candidate for gene delivery [2-8]. Its inherent biocompatibility, biodegradability, inorganic nature and ease of fabrication make it an attractive alternative to viral vehicles as gene delivery tools. Viruses are common and have high transfection efficacy, but can also be immunogenic and cytotoxic. Aside from gene delivery, HA-NPs by themselves or in combination with drugs have targeted specific cells showing promising results including tumor targeting [9-15]. In addition, the feasibility of rendering HANPs fluorescent and also magnetically active opens many possibilities in imaging and therapy, e.g. tumor ablation [4,16-20].

The two most attractive aspects of HA-based NPs are their inherent biocompatibility and biodegradability. Biocompatible carriers are essential to safely deliver genes/proteins/drugs into the cell without impairing the targeted site while degradability is of particular interest to overcome long-term cytotoxicity. Although these advantages have spurred numerous studies on the use of HANPs, there are contradictory results that arise from poor

\footnotetext{
a. Biomaterials, Biomechanics and Tissue Engineering Group, Department of Materials Science and Metallurgical Engineering, Technical University of Catalonia, Av. Diagonal 647, Barcelona 08028, Spain.

${ }^{b .}$ Centre for Research in Nanoengineering, Technical University of Catalonia,

Pascual i Vila 15, Barcelona 08028, Spain.

+ Electronic Supplementary Information (ESI) available: characterisation of codoped magnesium/carbonate hydroxyapatite nanoparticles and videos of tomographies showing NP internalization in MG63 by soft X-ray imaging

${ }^{\ddagger}$ These authors contributed equally to this work.

*Corresponding author. Email: Montserrat.espanol@upc.edu
}

characterization of the materials and their interaction with the target cells/site. Nevertheless, active research in this area is helping to build a more solid base in understanding of NPs-cell interaction.

It is well understood now that NPs features such as size, morphology, dose, surface charge and agglomeration state affect cell behavior, and therefore should be considered when using NPs in gene/protein/drug delivery applications. Similarly, it is clear that the response of NPs is cell dependent. The results pertaining to the analysis of such characteristics on HA-NPs are available [21-29], but it is important to stress that in some cases conclusions have been drawn from incomplete characterization studies.

One aspect that remains to be investigated is how changes in the composition of HA-NPs influence cell behavior. The crystal lattice of HA is well known for accommodating a wide range of ionic substitutions among which carbonate and $\mathrm{Mg}$ stand out as major anionic and cationic elements found in bone minerals [30-32]. The incorporation of ionic substitutions into HA-NPs is well documented $[30,33]$, but unfortunately many cell culture studies are lacking [3437] or focus on one type of ion substitution, which makes it difficult to compare results. Studies are often also performed on compressed NPs in molds [18,38-40]. These results cannot be used to explain the interaction of dispersed NPs with cells because NPs cannot be internalized (endocytosed or phagocytosed) in bulk.

Thus, our goal is to study if NP composition affects cell behavior to ensure optimal design of HA-NPs for cellular internalization applications. To allow comparison of results, all NPs were synthesized following the same protocol and thoroughly characterized. Cell culture studies were performed using MG-63 cells and and rat mesenchymal stem cells (rMSCs) under various conditions: 1) citrate-dispersed NPs and on agglomerated NPs and 2) in cell culture media containing or excluding $10 \mathrm{v} / \mathrm{v} \%$ of foetal bovine serum (FBS).

\section{Experimental section}

Synthesis and characterization of doped hydroxyapatite nanoparticles 
All HA-NPs were synthesized by neutralization of $\mathrm{Ca}(\mathrm{OH})_{2}$ with $\mathrm{H}_{3} \mathrm{PO}_{4}$ (Eq. 1) at $40{ }^{\circ} \mathrm{C}$ in air. The temperature was controlled by means of a thermal bath (Huber Kältemaschinenbau $\mathrm{GmbH}$, Germany), and the reaction was performed on thermojacketed vessels connected to the bath. The $\mathrm{pH}$ was continuously monitored throughout the reaction.

$$
10 \mathrm{Ca}(\mathrm{OH})_{2}+6 \mathrm{H}_{3} \mathrm{PO}_{4} \rightarrow \mathrm{Ca}_{10}\left(\mathrm{PO}_{4}\right)_{6}(\mathrm{OH})_{2}+18 \mathrm{H}_{2} \mathrm{O} \quad \text { Eq. (1) }
$$

The synthesis of the non-doped NPs was carried out as follows: $100 \mathrm{~mL}$ of $0.334 \mathrm{~mol} \mathrm{~L}^{-1} \mathrm{Ca}(\mathrm{OH})_{2}$ (Fluka, 96 wt\% pure) was first prepared and then a $0.2 \mathrm{M} \mathrm{H}_{3} \mathrm{PO}_{4}$ (Panreac, $85 \mathrm{wt} \%$ pure) solution was added dropwise into the system at the constant rate of 1 $\mathrm{mL} / \mathrm{min}$ under constant stirring. The reaction was stopped when the $\mathrm{pH}$ reached 8 . Next, the suspension was left stirring for 20-30 min and was then transferred into a glass bottle where it was left to mature overnight at room temperature. The next day, the suspension was rinsed with MilliQ water to constant conductivity following cycles of 5 min centrifugation at $800 \mathrm{~g}$ (Beckman Allegra 21 Benchtop Centrifuge)/re-suspension. Afterwards, the product was frozen at $-80{ }^{\circ} \mathrm{C}$ and lyophilized (Telstar Cryodos). Once lyophilized, the powder was kept in a desiccator.

To prepare carbonate-doped HA-NPs, different amounts of sodium hydrogen carbonate $\left(\mathrm{NaHCO}_{3}\right.$, Sigma-Aldrich, ReagentPlus ${ }^{\circledR}$, $\geq 99.5 \mathrm{wt} \%$ pure) were added to the $\mathrm{Ca}(\mathrm{OH})_{2}$ suspension prior to addition of the phosphoric acid. The amount of $\mathrm{CO}_{3}{ }^{2-}$ added was calculated so as to have 5, 10 and 20 wt\% of carbonate. Similarly, the synthesis of the Mg-doped NPs was achieved by mixing the calcium hydroxide suspension with $\mathrm{MgCl}_{2} \cdot 6 \mathrm{H}_{2} \mathrm{O}$ (Panreac, 99 wt\% pure) to get 5, 10 and $20 \mathrm{wt} \%$ of $\mathrm{Mg}^{2+}$. Co-substitution of carbonate and $\mathrm{Mg}$ was accomplished with a slight modification in the protocol [41]. The $\mathrm{Ca}(\mathrm{OH})_{2}$ powder was suspended in $80 \mathrm{~mL}$ (instead of 100 $\mathrm{mL}$ ) and the desired amount of $\mathrm{Mg}$ salt was dissolved into it. The carbonate salt was dissolved separately in $20 \mathrm{~mL}$ of water and added dropwise $\left(1 \mathrm{~mL} \mathrm{~min}^{-1}\right)$ into the basic suspension prior to the addition of the phosphoric acid. For this particular reaction, the addition of acid was stopped at $\mathrm{pH}$ 7. All other parameters were held constant. Maturation, rinsing and drying of the NPs was performed as stated above. The different NPs were designated as follows:

- HA: non-doped NPs,

- 5C, 10C, 20C: carbonate-doped HA-NPs (5, 10 and 20 wt\% respectively)

- 5M, 10M: magnesium-doped HA-NPs (5 and 10 wt\% respectively)

- $\quad 4 M / 7 C: 4$ wt\% magnesium and 7 wt\% carbonate codoped HA-NPs.

Characterization of the NPs was performed with multiple techniques. The phase composition was determined with $\mathrm{X}$-ray powder diffraction (XRD) using a D8 Advance Diffractometer (Bruker, Karlsruhe, Germany) with $\mathrm{Cu}$ K $\alpha$ radiation at $40 \mathrm{kV}$ and 40 $\mathrm{mA}$. The XRD spectra were recorded from $10-80^{\circ}$ with a step size of 0.02 and a counting time of $1 \mathrm{~s}$. The crystallite size of hydroxyapatite nanoparticles was calculated through the Scherrer formula as follows:

$$
X_{h k l}=K \cdot \lambda / \beta_{1 / 2} \cdot \cos \theta
$$

where $X_{\mathrm{hkl}}$ is the crystallite size $(\mathrm{nm}), \lambda$ is the wavelength of monochromatic $X$-ray beam $(\mathrm{nm})(0.15418 \mathrm{~nm}$ for CuK $\alpha$ radiation), $\beta_{1 / 2}$ is the full width at half maximum for the diffraction peak under consideration (rad), $\theta$ is the diffraction angle (in degrees), and $\mathrm{K}$ is a constant varying with crystal habit and here set to 0.9 .

Fourier transform infrared spectroscopy (FTIR) in the ATR mode (Attenuated Total Reflectance mode, Nicolet 6700 spectrometer, Thermo Scientific) was used to check the typical functional groups present in apatite and, in particular, the presence of carbonate bands in the powders. All spectra were obtained by averaging 32 scans collected from $500-4000 \mathrm{~cm}^{-1}$ with a spectral resolution of 4 $\mathrm{cm}^{-1}$.

Elemental carbon determination analysis (Thermo EA 1108 CHNS-O Thermo Scientific, Milan, Italy) was performed on $10 \mathrm{mg}$ of sample previously dehydrated at $120{ }^{\circ} \mathrm{C}$ to measure the amount of carbonate in the powders. The sample was pyrolyzed and combusted using vanadium oxide $\left(\mathrm{V}_{2} \mathrm{O}_{5}\right)$ as an oxidant at $1000{ }^{\circ} \mathrm{C}$ in an oxygen atmosphere and the resulting gaseous products were chromatographically separated and quantified to yield the concentration of carbon.

Quantitative inductively coupled plasma-optical emission spectrometry analysis (ICP-OES, Perkin Elmer Optima 3200RL) was used to determine the overall content of $\mathrm{Ca}, \mathrm{P}, \mathrm{Na}$ and $\mathrm{Mg}$. Samples were prepared by dissolving $100 \mathrm{mg}$ of powder in $5 \mathrm{~mL}$ of $10 \mathrm{wt} \%$ $\mathrm{HNO}_{3}$ (Panreac, $69 \mathrm{wt} \%$ pure) that was then 10 or 20 -fold diluted.

The specific surface area (SSA) of the NPs was determined from the nitrogen adsorption data in the relative pressure range $\left(P / P_{0}\right)$ from 0.05 to 0.35 with the Brunauer-Emmett-Teller (BET) method with a ASAP2020 physisorption analyzer (Micromeritics, Norcross, GA, USA). The sample was outgassed at $120^{\circ} \mathrm{C}$ before analysis.

The morphology of the NPs was assessed by transmission electron microscopy (TEM, JEOL 1010). Samples for TEM examination were prepared by soaking a 300 mesh carbon-coated copper grid in the solution of interest, blotting to remove excess liquid and air-dried.

The apparent solubility of the NPs was evaluated by monitoring the conductivity changes (Crison MM41) of a $0.1 \mathrm{~mol} \mathrm{~L}^{-1}$ acetate buffer solution $\left(25^{\circ} \mathrm{C}, \mathrm{pH}=5.5\right.$ ) containing $1 \mathrm{mg} \mathrm{mL}^{-1}$ of NPs with time.

\section{Nanoparticles dispersion}

NPs dispersion was achieved by mixing $0.1 \mathrm{~g}$ of the NPs with $10 \mathrm{~mL}$ of 1 wt\% sodium citrate solution $\left(\mathrm{C}_{6} \mathrm{H}_{5} \mathrm{Na}_{3} \mathrm{O}_{7} \cdot \mathrm{x} \mathrm{H}_{2} \mathrm{O}\right.$, Sigma-Aldrich, ReagentPlus, purity $\geq 99 \%$ ). To improve dispersion, the suspension was sonicated with a high frequency ultrasound probe sonicator (Branson Digital, Model 250W) to separate the agglomerates and facilitate citrate adsorption. The following settings/conditions were applied: $3 \mathrm{~mm}$ diameter tip, 40\% amplitude ( 50 Watts) and 2 minutes of sonication (with cycles of $15 \mathrm{sec}$ sonication followed by $10 \mathrm{sec}$ pause to prevent excessive heating) in an ice bath. Suspensions without citrate were also prepared following the same protocol but by replacing the $10 \mathrm{~mL}$ of $1 \mathrm{wt} \%$ sodium citrate solution with $10 \mathrm{~mL}$ of MilliQ water $\left(18.2 \mathrm{M} \Omega \mathrm{cm}^{-1}\right)$.

The amount of citrate adsorbed on the NPs was quantified with HPLC (high performance liquid chromatography, Alliance 2695, Waters) using a resin-based column adequate for the analysis of organic acids. Prior to measurement, the NP suspensions were filtered with a $0.22 \mu \mathrm{m}$ filter syringe to remove the NPs, and the NPfree solution free was measured. A calibration curve was prepared using known concentrations of trisodium citrate. The samples were 
injected into the column (Aminex HPX-87H, BioRad) using a mobile phase consisting of $10 \mathrm{mM}$ sulphuric acid at a flow rate of 0.8 $\mathrm{mL} / \mathrm{min}$ at $60{ }^{\circ} \mathrm{C}$. An ultraviolet-visible detector (Jasco UV-1970) at $210 \mathrm{~nm}$ was the detector to monitor the the $\mathrm{C}=\mathrm{O}$ double bond in citrate. The amount adsorbed was determined by difference between the initial citrate solution and the citrate remaining after NPs addition.

The NPs surface charge was determined by measuring the zeta potential of the NPs in milliQ water at a concentration of $250 \mu \mathrm{g} \mathrm{mL}^{-}$ ${ }^{1}$ of NPs (Zetasizer Nano-ZS from Malvern Instruments Ltd., UK). Prior to measurement, the stock suspensions of 1 wt\% NPs dispersed in either $1 \mathrm{wt} \%$ citrate or water were first diluted in cell culture media (DMEM, Dulbecco's Modified Eagle medium) containing or excluding $10 \mathrm{v} / \mathrm{v} \%$ FBS (Foetal Bovine serum) to achieve a final concentration of $1000 \mu \mathrm{g} \mathrm{mL}^{-1}$ of NPs. The mixture was then allowed to interact for a couple of hours, and the NPs were next centrifuged, rinsed with milliQ water and resuspended with milliQ water to make the final concentration $250 \mu \mathrm{g} \mathrm{mL}^{-1}$ prior to measurement.

To note, all cell culture tests performed on citrate dispersed NPs were performed without removing the unbound citrate from the suspension to prevent any desorption from the NPs upon citrate depletion.

\section{Cell culture studies}

Human osteoblast-like MG-63 cell line and rat mesenchymal stem cells were cultured in Dulbecco's Modified Eagle medium (DMEM) or advanced DMEM, respectively, containing $10 \mathrm{v} / \mathrm{v} \%$ foetal bovine serum (FBS), penicillin/streptomycin $\left(50 \mathrm{U} \mathrm{mL}^{-1}\right.$ and $50 \mu \mathrm{g} \mathrm{m}^{-1}$, respectively), $2 \mathrm{mmol} \mathrm{L}^{-1} \mathrm{~L}$-glutamine and $20 \mathrm{mmol} \mathrm{L}^{-1} \mathrm{HEPES}$ buffer at $37{ }^{\circ} \mathrm{C}$ in a humidified atmosphere at $5 \% \mathrm{CO}_{2}$. When cells attained confluence, they were detached using $0.25 \%$ Trypsin and seeded onto standard polystyrene tissue culture plates (96 wells) at a cell density of $1 \times 10^{4}$ cells well ${ }^{-1}$. The seeded cells were incubated overnight to allow cell adhesion prior to adding the NPs.

\section{Exposure of cells to doped and non-doped NPs}

Cells were exposed to all NPs (dispersed in citrate or in water) in two different scenarios: in cell culture media supplemented with 10 v/v\% FBS and without FBS. The appropriate volume of NPs from the stock (1 wt\% NPs in either $1 \mathrm{wt} \%$ of sodium citrate or water) was added to the corresponding cell culture media to make a final concentration of $100 \mu \mathrm{gL}^{-1}$. Before adding the suspensions to the cells, the mixture was vortexed to homogenize it. The incubation period was $24 \mathrm{~h}$. For selected compositions (i.e., HA and 10M) the same experiment was performed using transwells by placing the NPs on the transwells to prevent direct contact of the NPs with the cells but allowing any ionic exchange through the transwell membrane $(6.5 \mathrm{~mm}$ Transwell with $0.4 \mu \mathrm{m}$ pore polyester membrane insert for 24 well plates from Sigma). The number of cells seeded on the 24 well plates was $2.5 \times 10^{4}$ cells well $^{-1}$, and the concentration of NPs was $100 \mu \mathrm{gL}^{-1}$.

To study the effect of NP dose on cytotoxicity, the amount of 10 $M$ NPs in cell culture media was increased with the following concentrations: $100,250,500$, and $1000 \mu \mathrm{g} \mathrm{m}^{-1}$. Non-doped HA was also included as a control.

\section{Cytotoxicity test}

For cytotoxicity evaluation of various NPs, the cell culture medium was removed after $24 \mathrm{~h}$ of incubation time. The viable cells attached on the surface of polystyrene tissue culture plates were lysed with $100 \mu \mathrm{L}$ of mammalian protein extraction reagent (M-PER, Thermo Scientific Inc., USA). Upon lysis, the cells released lactate dehydrogenase (LDH) that was measured using a commercially available kit (Cytotoxicity Detection KitPLUS, Roche, USA) following the manufacturer's instructions. The absorbance at $492 \mathrm{~nm}$ was quantified on a micro spectrophotometer (PowerWave XS, Bio-Tek Instruments, USA), and the percentage of viability was calculated by the following equation:

$$
\text { viability } \%=\frac{\text { exp. value }- \text { negative control }}{\text { positive control }- \text { negative control }} \times 100
$$

Here, the 'positive control' was the absorbance value of cells incubated in cell culture medium under the same conditions of the experimental value but without NPs and the 'negative control' corresponded to the absorbance of the well without NPs and without cells. The studies done in triplicate were expressed as mean \pm standard error of the mean. The Kruskal-Wallis non-parametric test and the Mann-Whitney test with Bonferroni correction were used to determine statistical significance ( $p$-value $<0.05$ ) between the means of the different groups.

Table 1 Compilation of various characteristics of the NPs.

\begin{tabular}{lccccccc}
\hline & $\begin{array}{c}\mathbf{C O}^{2}{ }^{2-} \\
\text { wt \% }\end{array}$ & $\begin{array}{c}\mathbf{M g}^{2+} \\
\mathbf{w t} \%\end{array}$ & $\begin{array}{c}\mathbf{N a}^{+} \\
\mathbf{w t} \%\end{array}$ & $\begin{array}{c}\mathrm{Ca} / \mathrm{P} \\
\text { Atomic }\end{array}$ & $\begin{array}{c}\text { (Ca+Mg)/P } \\
\text { atomic }\end{array}$ & $\begin{array}{c}\text { SSA } \\
\mathbf{m}^{2} / \mathbf{g}\end{array}$ & \multicolumn{2}{c}{$\begin{array}{c}\text { Crystallite size (002) } \\
\mathbf{N m}\end{array}$} \\
\hline $\mathbf{H A}$ & $2.46 \pm 0.03$ & $0.27 \pm 0.01$ & 0 & $1.76 \pm 0.03$ & $1.78 \pm 0.03$ & $93.55 \pm 0.32$ & 28.2 \\
$\mathbf{5 C}$ & $6.63 \pm 0.42$ & $0.26 \pm 0.01$ & $0.23 \pm 0.07$ & $1.85 \pm 0.04$ & $1.89 \pm 0.06$ & $87.04 \pm 0.34$ & 26.0 \\
$\mathbf{1 0 C}$ & $10.1 \pm 0.20$ & $0.26 \pm 0.01$ & $0.35 \pm 0.07$ & $1.92 \pm 0.03$ & $1.94 \pm 0.02$ & $74.61 \pm 0.32$ & 25.5 \\
$\mathbf{2 0 C}$ & $11.4 \pm 0.40$ & $0.26 \pm 0.01$ & 0.54 & $2.07 \pm 0.03$ & $2.10 \pm 0.03$ & $48.42 \pm 0.17$ & 23.4 \\
$\mathbf{5 M}$ & n.d. & $1.23 \pm 0.01$ & 0 & $1.68 \pm 0.06$ & $1.77 \pm 0.04$ & $103.32 \pm 0.43$ & 27.4 \\
$\mathbf{1 0 M}$ & n.d. & $2.32 \pm 0.25$ & 0 & $1.57 \pm 0.02$ & $1.77 \pm 0.01$ & $85.19 \pm 0.41$ & 24.8 \\
$\mathbf{4 M 7 C}$ & 7.8 & $1.51 \pm 0.01$ & $0.05 \pm 0.01$ & $1.77 \pm 0.03$ & $1.91 \pm 0.03$ & $59.83 \pm 0.29$ & 25.1 \\
\hline
\end{tabular}

Measures performed on two independent batches for every NP-type except for the SSA where only one batch was measured. 


\section{Cellular uptake of NPs}

TEM and soft X-ray imaging were used to visualize MG63 cellular uptake of HA and $10 \mathrm{M}$ NPs dispersed in milliQ water.

For TEM imaging cells were exposed for $24 \mathrm{~h}$ to the NPs in cell culture media excluding FBS. The cultured cells were then fixed with $2.5 \mathrm{wt} \%$ glutaraldehyde in $0.1 \mathrm{~mol} \mathrm{~L}^{-1}$ phosphate buffer for $1 \mathrm{~h} 30 \mathrm{~min}$ at room temperature and both the media and the film formed at the bottom of the well were detached and centrifuged to form a pellet. The pellet was then rinsed prior to adding 1 wt\% osmium tetroxide and dehydrated in an ascending series of acetone solution up to $100 \%$ and infiltrated with EPON12 resin. Upon resin polymerization (48 h, $60{ }^{\circ} \mathrm{C}$ ) blocks were sectioned using an ultramicrotome (Ultracut UCT, Leica Microsystems $\mathrm{GmbH}$, Vienna, Austria). The sections were stained with 2 wt\% uranyl acetate and imaged with an optical microscope (Leica DM2000 LED, Leica Microsystems $\mathrm{GmbH}$, Vienna, Austria) and transmission electron microscopy (Tecnai Spirit FEl, Eindhoven, The Netherlands).

For soft X-ray imaging, Quantifoil R2/2 Au G200F1 finder grids were pre-coated with fibronectin (Sigma, F2006) prior to MG63 seeding. After overnight cell attachment, the cell culture media was replaced by fresh media containing NPs but without FBS. NPs were allowed to interact with cells for 2-3 $\mathrm{h}$. Afterwards the grids were gently rinsed with PBS and immediately plunged freeze to vitrify cells and stored in liquid nitrogen tanks till observation. Cryo transmission soft $\mathrm{X}$-ray imaging was made at the MISTRAL beamline in the Synchrotron facilities from Alba (Cerdanyola, Spain). Tomographic series were collected at $520 \mathrm{eV}$ irradiating the cell for a few seconds $(2-10 \mathrm{sec})$ per section at a spatial resolution down to $30 \mathrm{~nm}$.

\section{Results and discussion}

\section{Characterization of carbonate-doped nanoparticles}

Figure 1 shows the XRD and FTIR patterns of the NPS synthesized with various concentrations of carbonate, i.e. 0,5 , 10 and $20 \mathrm{wt} \%$. The XRD results (Figure $1 \mathrm{~A}$ ) showed that all synthesized NPs were phase pure with no peaks other than those assigned to HA (ICDD No. 9-432). Moreover, the broad peaks in all samples showed the poor crystallinity of the NPs. This was also reflected in the small crystallite sizes (size of the coherently scattering domains) calculated for all NPs regardless of composition while considering the diffraction peak corresponding to the (002) reflection (Table 1). A detailed examination of the XRD data for the different NPs revealed additional characteristics. Carbonation caused a marked decrease in the intensity of the (00x) reflections with a shift towards lower $2 \theta$ angles. The first of these two features was indicative of a change in the crystal morphology. The later suggested incorporation of carbonate into the apatite lattice replacing the phosphate groups (B-type substitution) [42]. The FTIR results (Figure 1B) further confirmed the B-type substitution, which is typical of hydroxyapatites precipitated at low temperature via the presence of specific bands-the asymmetric stretch vibration, v3, at 1430 and $1450 \mathrm{~cm}^{-1}$ and the out-of-plane bend vibration, $v_{2}$, close to $870 \mathrm{~cm}^{-1}$ [43]. An additional feature observed from both XRD and FTIR was the loss in the resolution of the peaks and bands that were explained by the crystal distortion provoked by carbonate incorporation.

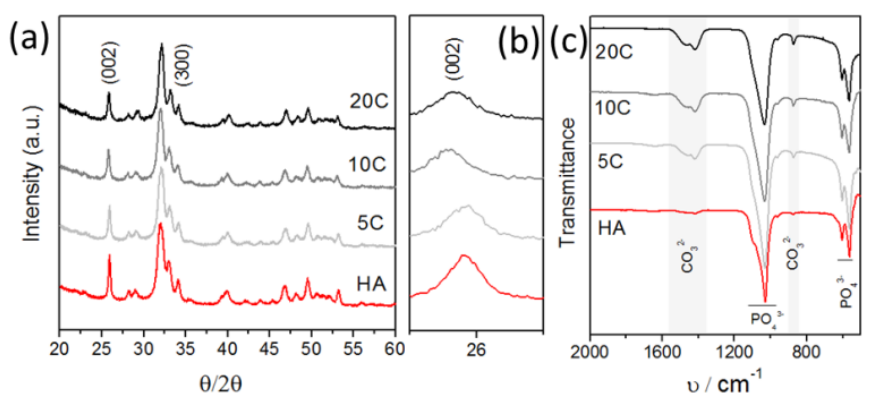

Figure 1 (a) X-Ray diffraction data for the different NPs: nondoped (HA) and NPs doped with various carbonate contents, (b) detail of the peak shift corresponding to the (002) reflection with carbonate content and, (c) FTIR spectra of the various compositions.

Despite the fact that during synthesis specific amounts of carbonate salt were added, the exact amount incorporated in the NPs differed from the nominal value (Table 1 ). The 2.46 wt\% of carbonate observed in NPs prepared without adding any carbonate salt is caused by the traces of carbonate present in the $\mathrm{Ca}(\mathrm{OH})_{2}$ powder and also by the dissolution of carbon dioxide in the solution reaction during precipitation.

There is a limited increase in carbonate uptake by the NPs when adding $20 \mathrm{wt} \%$ of $\mathrm{NaHCO}_{3}$ versus $10 \mathrm{wt} \%$. For the 10 wt\% reaction, 10 wt\% is incorporated but for the 20 wt\% only $11 \mathrm{wt} \%$ of carbonate is incorporated. This shows that carbonate saturation occurred in the apatite. The ICP-MS results (Table 1) showed that the incorporation of carbonate was accompanied by $\mathrm{Na}$ incorporation. This co-substitution is very common as it helps balancing the charges in the exchange of $\mathrm{PO}_{4}{ }^{3-}$ by $\mathrm{CO}_{3}{ }^{2-}$ [37].

The incorporation of carbonate in the apatite lattice had a marked effect on the morphology of the NPs (Figure 2a). The NPs changed from a needle-like shape to a more isotropic shape with increasing carbonate content similar to other reports [44]. Such a change in shape was already hinted at the XRD data by the decrease in intensity of the (00x) reflections for the higher carbonate-containing NPs. Indeed, it is known that needle-like HA crystals exhibit preferential growth along the $c$ axis, which translates into a selective increase in the (00x) diffraction peaks. Thus, it is not surprising to find that more isotropic crystals should result in an "intensity" decrease because such peaks are observed with an increase in carbonation (Figure 1). Not only does the shape become more isotropic but also the SSA decreases with carbonation (Table 1). This decrease in SSA can be explained from two different perspectives. On one hand, the morphological changes reveal a clear increase in NP width for a similar length. This is 
especially true for $20 \mathrm{C}$ NPs when compared to non-doped HA NPs. This thickening of the NPs is one of the arguments to explain the reduction in their SSA. However, it has also been reported that freeze-drying of NPs can induce aggregation [45]. In this regards, the decrease in crystallinity with carbonation could particularly favour crystal fusion during the drying process and thus reduce their SSA. The incorporation of carbonate in the structure of HA was further proved from the increase in their solubility as indicated by the increase in conductivity (Figure $2 b$ ). (a)

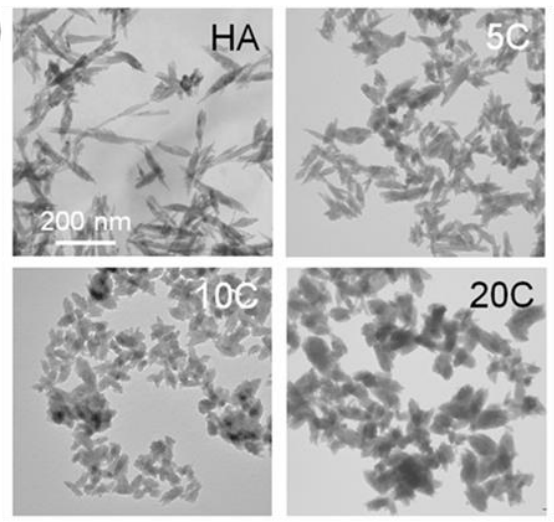

(b) 6

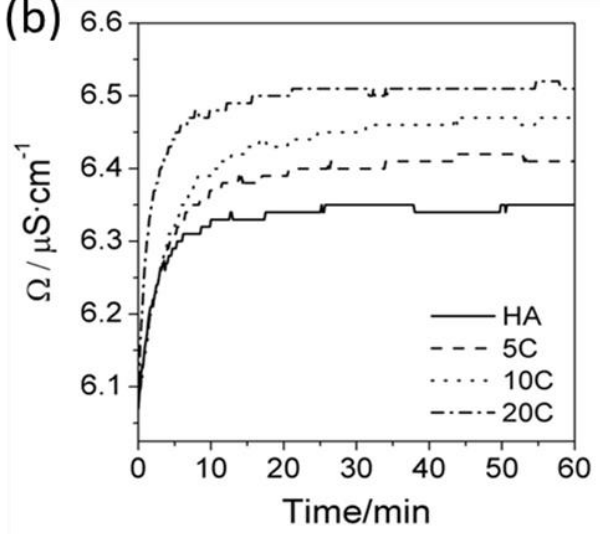

observed for the carbonate-doped NPs, not all Mg that was added in the synthesis reaction became incorporated into the crystal structure. Substitution of $\mathrm{Mg}$ for $\mathrm{Ca}$ in the structure of HA occurs over a limited composition range (up to about 10 at.\% [30]).
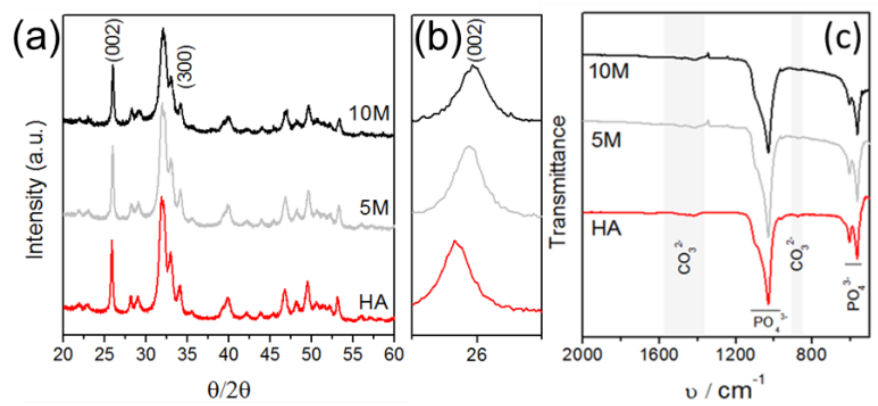

Figure 3 (a) X-Ray diffraction data for the different NPs: nondoped (HA) and NPs doped with various Mg contents. (b) Detail of the peak shift corresponding to the (002) reflection with $\mathrm{Mg}$ content and, (c) FTIR spectra of the various compositions.

(a)
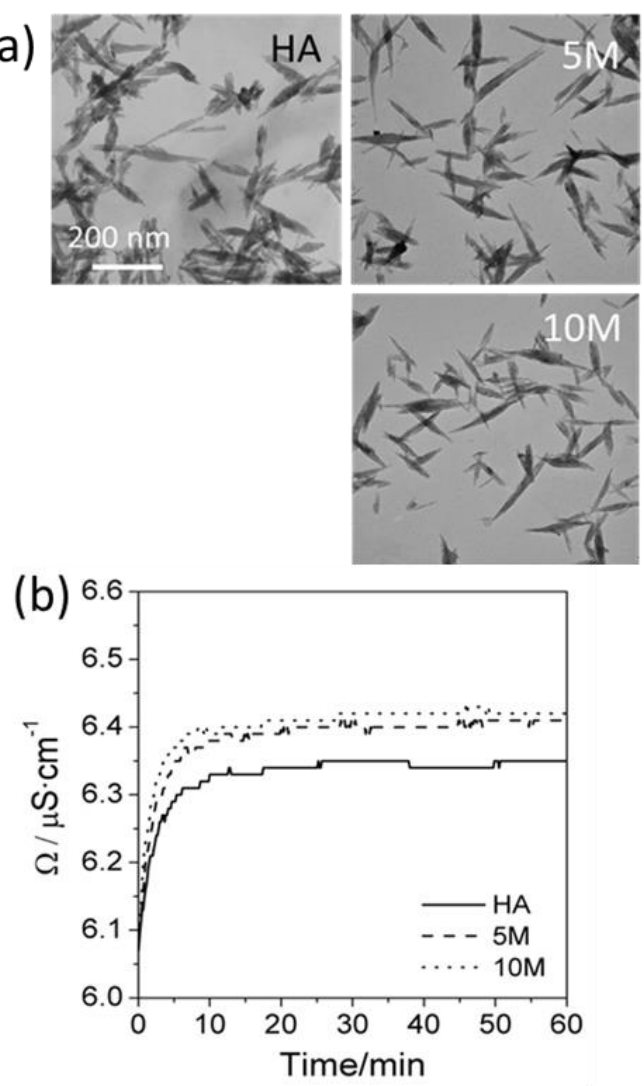

Figure 2 (a) TEM micrographs of the non-doped (HA) and carbonate-doped NPs and (b) apparent solubility curves determined through conductivity measurements for the various NPs.

\section{Characterization of magnesium-doped nanoparticles}

XRD and FTIR results pertaining to the synthesis of Mg-doped NPs are summarized in Figure 3. Similar to what was achieved for the carbonate-doped NPs, Mg containing NPs are also phase-pure because no peaks of foreign phases were detected by XRD. The addition of Mg salt during synthesis led to slightly broader peaks in the XRD pattern, which accounted for a decrease in the crystallinity of the NPs with increasing $\mathrm{Mg}$ content. The slight shift of the (002) diffraction peak (Fig. 3b) for Mg-substituted samples is due to contraction of the cell lattice parameters of HA caused by the smaller ionic radius of the $\mathrm{Mg}$ cation compared to calcium [46]. XRD thus proves that at least some of the $\mathrm{Mg}$ cations have indeed been incorporated into the HAP structure. Similarly to what was
Figure 4 (a) TEM micrographs of the non-doped (HA) and magnesium-doped NPs. (b) Apparent solubility curves determined through conductivity measurements for the various NPs.

$\mathrm{Mg}$ incorporation was further confirmed by ICP-OES analysis (Table 1). The atomic ratio $(\mathrm{Ca}+\mathrm{Mg}) / \mathrm{P}$ was maintained regardless of the $\mathrm{Mg}$ content, which suggests that $\mathrm{Mg}$ was replacing Ca rather than becoming adsorbed on the surface of the nanocrystals. Furthermore, it has been reported that the 
incorporation of low $\mathrm{Mg}$ contents in the $\mathrm{HA}$ structure preserves the $(\mathrm{Ca}+\mathrm{Mg}) / \mathrm{P}$ stoichiometry [46]. $\mathrm{Mg}$ incorporation slightly influenced the FTIR spectra-there was a loss in the resolution of the bands (Figure $3 \mathrm{c}$ ). Carbonate was also present in the Mg-doped NPs as can be detected from the FTIR analyses. The level of carbonate was similar to that found in the "non-doped" HA. As explained earlier, carbonation was due to the presence of carbonate in the $\mathrm{Ca}(\mathrm{OH})_{2}$ reagent and also from atmospheric carbon dioxide.

Despite the incorporation of $\mathrm{Mg}$ inside the crystal lattice, the morphology of the Mg-doped NPs was not altered as shown by the identical size and needle-like shape to the nondoped ones (Figure 4). This was probably due to the low content of $\mathrm{Mg}$ incorporated. The solubility of the $\mathrm{Mg}$-doped NPs slightly increased versus non-doped HA NPs - there was no significant differences between $5 \mathrm{M}$ and $10 \mathrm{M}$ (Table 1 ). This increase in solubility is consistent with the distortion that Mg causes when enters in the crystal lattice of HA (owing to the mismatch between ion sizes) and the decrease in crystallinity. Similar SSA values were also obtained for the Mgdoped and non-doped HA (Table 1).

\section{Characterization of magnesium/ carbonate-doped nanoparticles}

Co-doping with both $\mathrm{Mg}$ and carbonate led to NPs sharing characteristics of both substitutions. The presence of $\mathrm{Mg}$ and carbonate was verified by ICP and elemental carbon determination, respectively. Co-doping slightly facilitated the introduction of $\mathrm{Mg}$ into the HA crystal lattice as observed from the 1.52 wt\% content that was superior to that found for noncarbonated Mg-NPs. This could be explained from the more open and distorted crystal lattice that results from carbonate incorporation.

One uncertainty that often exists in the synthesis of doped hydroxyapatite NPs is whether ions get incorporated into the crystal structure or they simply adsorb on the surface of the NPs in the so-called hydrated layer [47]. The simultaneous incorporation of carbonate and magnesium makes it very difficult to determine this. The fact that ion-substitution is often associated to a loss in crystallinity prevents accurate evaluation of crystal lattice parameters by conventional XRD.

\section{Dispersion behavior and surface charge of the various ion doped NPs}

The high surface energy inherent to NPs inevitably causes aggregation. The addition of tri-sodium citrate with a high affinity for $\mathrm{HA}$ is a common strategy to prevent aggregation by conferring the NPs with a net negative charge. The interaction of citrate ions with apatites occurs via surface ionic exchanges of citrate for phosphate and the concomitant re-structuring of the hydrated layer surrounding the NPs $[48,49]$. Although other dispersing molecules could have been used, citrate was selected because of its biocompatibility and presence in bone (citrate accounts for 5.5 wt\% of the organic matter in bone) [50]. Quantification of the citrate content in the NPs showed that they contained between 2.6-4.6 wt\% (Table 2). As expected, the presence of citrate in the NP dispersion in cell culture media formed a colloidal suspension. Without citrate, the samples slowly settled out of solution.

Table 2 Surface charge and citrate content in the NPs under various conditions.

\begin{tabular}{lccccc}
\hline & $\begin{array}{c}\zeta\left(\mathrm{H}_{\mathbf{2}} \mathbf{0}\right) \\
\mathbf{m V}\end{array}$ & $\begin{array}{c}\zeta\left(\mathrm{FBS} / \mathrm{H}_{2} \mathbf{0}\right) \\
\mathbf{M v}\end{array}$ & $\begin{array}{c}\zeta \text { (citr)* } \\
\mathbf{m V}\end{array}$ & $\begin{array}{c}\zeta \text { (FBS/citr.) } \\
\mathbf{m V}\end{array}$ & $\begin{array}{c}\text { Citr. ads. } \\
\%\end{array}$ \\
\hline $\mathbf{H A}$ & $+4.0 \pm 0.1$ & $-20.1 \pm 0.3$ & $-13.3 \pm 0.5$ & $-23.3 \pm 1.5$ & $3.99 \pm 0.05$ \\
$\mathbf{5 C}$ & $+1.4 \pm 0.1$ & $-19.8 \pm 1.0$ & $-14.2 \pm 0.6$ & $-22.4 \pm 0.6$ & $4.62 \pm 0.53$ \\
$\mathbf{1 0 C}$ & $+1.3 \pm 0.1$ & $-19.2 \pm 0.7$ & $-13.6 \pm 0.3$ & $-21.9 \pm 0.6$ & $4.15 \pm 0.02$ \\
$\mathbf{5 M}$ & $+1.0 \pm 0.1$ & $-17.9 \pm 0.3$ & $-15.5 \pm 0.4$ & $-23.9 \pm 0.3$ & $2.93 \pm 0.61$ \\
$\mathbf{1 0 M}$ & $-1.7 \pm 0.1$ & $-17.1 \pm 0.2$ & $-13.3 \pm 0.4$ & $-19.8 \pm 0.5$ & $2.58 \pm 0.47$ \\
\hline $\mathbf{4 M 7 C}$ & $-1.7 \pm 0.1$ & $-20.3 \pm 0.3$ & $-11.2 \pm 0.5$ & $-20.3 \pm 0.4$ & $3.24 \pm 0.15$ \\
\hline
\end{tabular}

*Values slightly underestimated due to the rinsing step applied prior to measurement. Rinsing might have partially desorbed citrate from the NPs surface.

The surface charge of the NPs pre-incubated in various conditions and subsequently centrifuged and resuspended in water prior to measurement (removal of salts was required to minimize damage of the electrodes) is summarized in Table 2. Pre-incubation of citrate-dispersed and non-dispersed NPs was done in cell culture media (DMEM) including/excluding $10 \mathrm{v} / \mathrm{v} \%$ of FBS. As can be seen, the surface charge of the bare NPs (without citrate and without FBS) is low in terms of absolute value. When FBS, citrate or a mixture of both was added, the surface charge clearly became negative due to the adsorption of proteins and citrate on the surface of the NPs [51]. No significant differences in surface charge were detected among the different NP compositions regardless of the pre-incubation conditions. Of note, values for 20C NPs are not included in Table 2 because we did not succeed in adequately dispersing the NPs in citrate. We believe that the bigger dimensions of the NPs compromised their colloidal stability despite the presence of citrate. Thus, we did not pursue this category further.

\section{Cytotoxicity of ion doped NPs}

The main goal of the present work was to investigate the cytotoxic behaviour of ion-doped HA-NPs to explore how the presence of foreign ions could affect cellular internalization. Unfortunately, doping, besides incorporating the foreign ion/s can cause morphological and physicochemical changes in the structure of the NPs as demonstrated in the previous sections. This has to be considered in the interpretation of results.

\section{Cytotoxicity on MG63 cells}

Figure 5 shows cell viability after incubating MG63 cells with $100 \mu \mathrm{g} \mathrm{mL} \mathrm{m}^{-1} \mathrm{NPs}$ for $24 \mathrm{~h}$. Four different conditions were explored. We investigated the effect of well dispersed (+NaCit) versus as-prepared (-NaCit) NPs as well as the effect of adding or excluding $10 \mathrm{v} / \mathrm{v} \%$ FBS (+FBS or -FBS respectively) during cell culture. Both the adsorption of dispersant and proteins from FBS on the surface of the NPs can substantially change the surface properties of the NPs that in turn affects cell internalization [52]. Thus, it was interesting to study in an environment free of dispersant and proteins the real effect of the bare NPs even though if this would cause NPs 
agglomeration. The studies performed with the bare material provide unique information even if agglomeration/aggregation presumably affect the reproducibility of the experiments and hampers the targeting efficiency of the nanoparticles for cells and influences the degree of uptake and toxicity [53,54].

Results in Figure 5 clearly showed that for MG63 cells, NPs dispersed in sodium citrate-regardless of the presence of FBS in the cell culture media-were not cytotoxic as shown by the high percentage of viable cells. Experiments without dispersant showed NP sedimentation that formed a layer on top of the cells after $24 \mathrm{~h}$ of cell culture. This occurred regardless of the presence of FBS (Figure 5). Interestingly, under these circumstances, when NPs were cultured in the presence of FBS, viability was preserved for all NPs compositions. However, when the experiments were carried out on the bare NPs, 10M and 4M7C NPs were cytotoxic.
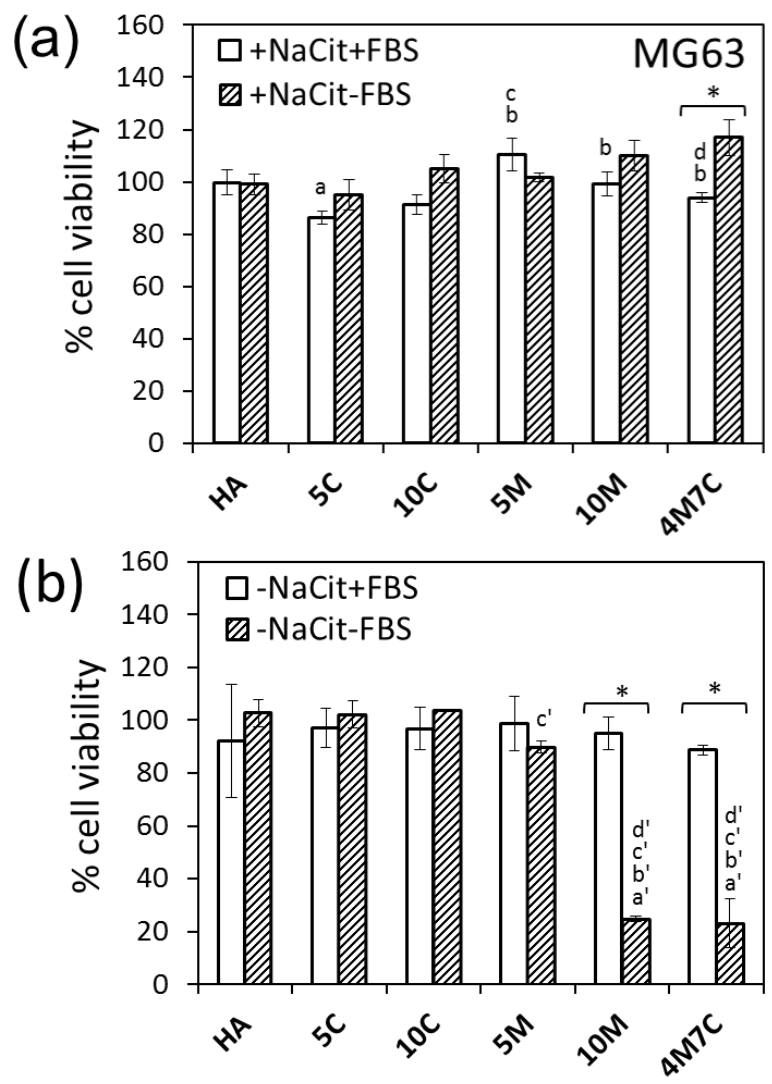

Figure 5 Viability of MG63 cells exposed to $100 \mu \mathrm{g} \mathrm{mL}^{-1}$ of the various NPs formulations for $24 \mathrm{~h}$. (a) Cells exposed to NPs dispersed in citrate in the presence or absence of $10 \mathrm{v} / \mathrm{v} \%$ FBS and (b) cells exposed to NPs dispersed in water in the presence or absence of $10 \mathrm{v} / \mathrm{v} \%$ FBS. Letters indicate significant differences among NPs cultured with FBS: a- indicates differences with $\mathrm{HA}, \mathrm{b}$ - differences with $5 \mathrm{C}$, c- differences with $10 \mathrm{C}$, d- differences with $5 \mathrm{M}$ and e- differences with $10 \mathrm{M}$. Letters with (') indicate significant differences among NPs cultured without FBS $(\mathrm{P}<0.05, \mathrm{~N}=3)$. The * indicates significant differences for the same type of NPs cultured with and without FBS $(P<0.05, N=3)$.

Experiments performed using different batches of NPs consistently confirmed the results. The experiments indicate that a specific content of $\mathrm{Mg}(10 \mathrm{M}$ and $4 \mathrm{M} 7 \mathrm{C}$ were 2.3 and 1.5 $w t \%$, respectively) was needed to trigger such a response. The fact that $5 \mathrm{M}$ with $\mathrm{Mg}$ content close to that of $4 \mathrm{M} 7 \mathrm{C}$ did not show the same behaviour could be related to the lower solubility of this NP. Unfortunately the synthesis of Mg-doped NPs with higher doping contents did not result in a phase-pure compound impeding corroboration of the cytotoxic effect using HA-NPs with even higher contents of $\mathrm{Mg}$.

It is interesting to discuss all cell culture results and consider the specific features that surrounded each study and each NP. Because $10 \mathrm{M}$ and $4 \mathrm{M} 7 \mathrm{C}$ NPs induced cytotoxicity in a specific scenario (in absence of sodium citrate and FBS), it seems reasonable to think that these particular NPs in all other scenarios (with FBS and/or citrate) were probably non cytotoxic simply because they could not be internalized (or they were less internalized). A very straightforward explanation to this could be the surface charge. The high affinity of citrate and proteins for hydroxyapatite is very well known [55-56]. Upon adsorption, both give the surface a negative charge (Table 1 ) that could then prevent/minimize internalization due to electrostatic repulsion with the cell membrane [26]. This occurs regardless of whether the NPs are dispersed (citrate) or not (without citrate but with FBS). It is not clear whether the lack of cytotoxicity in the remaining bare NPs (HA, 5C, 10C and 5M cultured without citrate and FBS) was due to a lack of internalization or to a non-toxic response upon internalization.

To prove if NP internalization in the absence of dispersant and FBS was indeed occurring, HA and 10M NPs were examined under TEM (Figure 6). The results not only proved that in both cases there were NPs entering the cells, but it also showed that 10M NPs caused considerable damage to the cell cytoplasm. However, it is also evident from the TEM images that processing, in particular the step of cell sectioning, had induced NP detachment masking the results. This was probably caused by limited resin penetration but also to the mismatch in stiffness between NPs and the resin during sectioning. To circumvent this problem NP internalization was also assessed by cryo-transmission using soft X-ray imaging at the synchrotron facilities in Alba. This technique needs only to vitrify hydrated cells prior to observation. Since no processing is required, pristine cells can be observed without fear of introducing artifacts. In the supplementary information two tomographic series (videos) show a sequence of $10 \times 10 \mu \mathrm{m}^{2}$ images inside a cell (MG63) after internalization of HA and $10 M$ NPs respectively. Relevant slices of the tomographic series are compiled in Figure 7 to prove the presence of vesicles containing NPs inside the cell. 


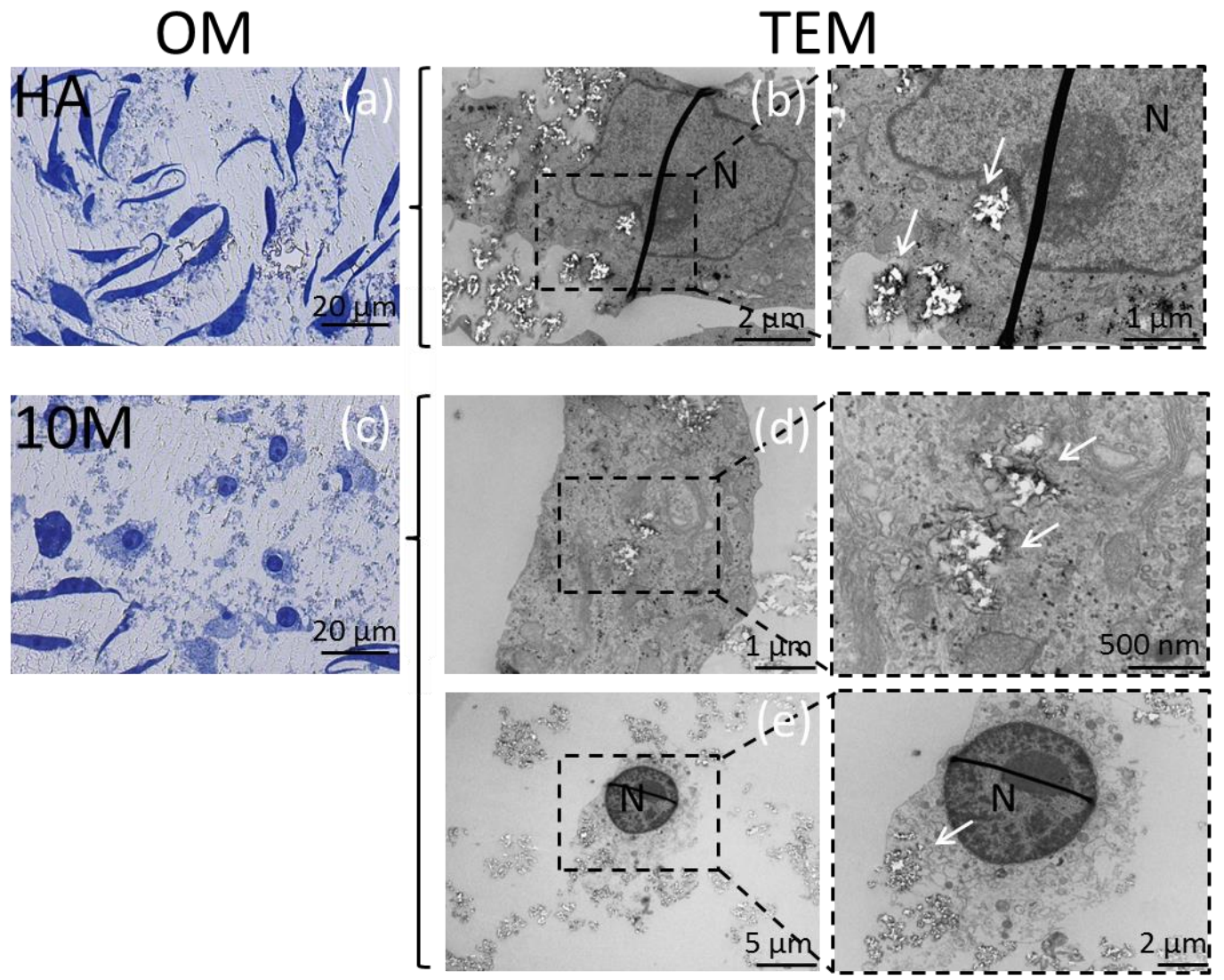

Figure $6(\mathrm{a}, \mathrm{c})$ Low magnification optical micrographs of stained MG63 cell sections showing excellent morphologies for the nondoped HA NPs (a), and damaged cell membrane for the Mg-doped 10M NPs (c). Panels $b$, $d$, and e are TEM micrographs of stained cell sections proving that NPs are internalized in both the HA (b) and 10M NPs (d, e). Arrows indicate NPs. White regions in the TEM micrographs correspond to regions were NPs were present but became detached during sectioning. Close to these regions elongated NPs can still be distinguished. $\mathrm{N}$ denotes cell nucleus. 

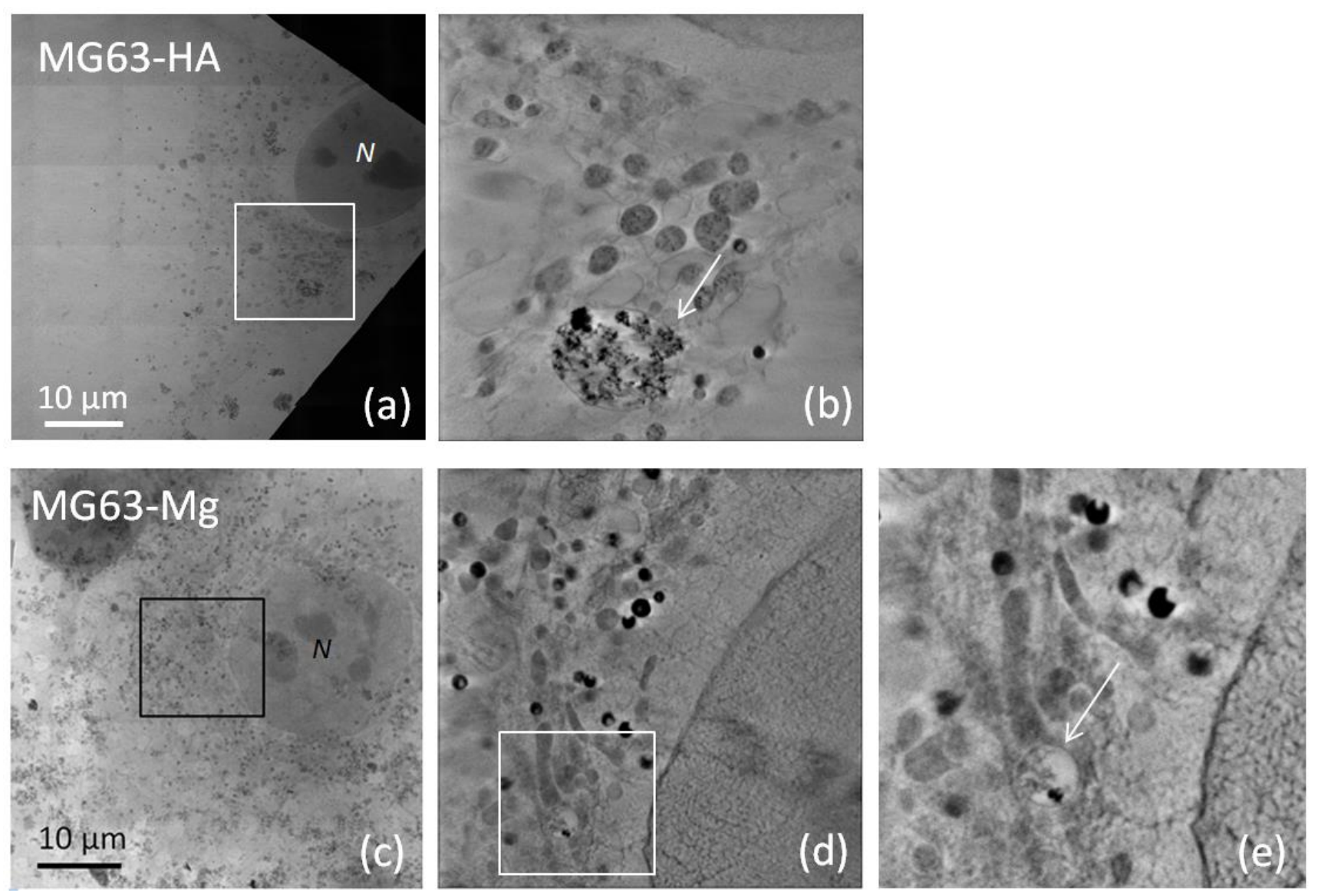

Figure 7 Cryo transmission soft X-ray images of vitrified unstained cells. (a, c) General view of the cell of interest across its whole thickness. (b, d, e) Images of individual slices showing vesicles containing NPs. (a, b) Results pertaining to internalisation of HANPs in MG63 in the absence of FBS and citrate. (c, d, e) Results pertaining to internalisation of $10 \mathrm{M}$ NPs in MG63 in the absence of FBS and citrate. Arrows point vesicles containing NP. N denotes cell nucleus. The videos of the whole tomographic series can be found in the Supplementary information.

Besides corroboration by TEM and soft X-ray imaging NP internalization, two additional experiments were then performed to prove that $10 \mathrm{M}$ NPs had to enter the cell to be cytotoxic (Figure 8). In the first experiment, cells were cultured in media supplemented with different concentrations of $\mathrm{Mg}^{2+}$ (without NPs) corresponding to the amounts of $\mathrm{Mg}$ doped in the $10 \mathrm{M}$ (2.2 wt\%) formulation. This was to prove if $\mathrm{Mg}$ ions released from the NPs could be the source of cytotoxicity. In the second experiment, cells were cultured in well plates and NPs were either placed in direct contact with cells (dispersed in cell culture medium) or in transwells (inserts). The NPs placed in transwells would not come into direct contact with cells-any ionic exchange would still be possible through the transwell membrane. The results clearly demonstrated that $10 \mathrm{M}$ were only cytotoxic if in direct contact with the cells but not when NPs were placed inside the transwell (Fig. 8b). Moreover, the fact that the addition of $\mathrm{Mg}$ salt did not affect cell viability (Fig. 8a) also suggested that the cytotoxicity of $10 \mathrm{M}$ NPs was due to NP internalization.

Interestingly, unlike $10 \mathrm{M}$ and $4 \mathrm{M} 7 \mathrm{C}$, internalization of $\mathrm{HA}$ NPs (Figure 6, 7) did not induce any toxic response under the conditions studied here (Figure 5). To further investigate this point, cells were cultured with increasing amounts of NPs for the $\mathrm{HA}$ and $10 \mathrm{M}$ formulations to enhance internalization (Figure 9). The results revealed that the bare HA-NPs (i.e., when citrate and FBS was excluded in the cell culture) induced cytotoxicity in a dose dependent manner (Figure 9). For 10M, cytotoxicity was also evident though no trend could be detected with dose. The fact that even after increasing the NPs dose only the "bare" NPs, but not the NPs adsorbed with citrate and/or FBS were cytotoxic, reinforced the fact that citrate and FBS might be hampering internalization. It is worth stressing that it was not because NPs were well dispersed (citrate) that minimized internalization. Indeed, without citrate but with FBS, the NPs sediment, but this did not increase internalization (Fig. 9). This finding reveals how critical surface charge is for this particular cell type. It reinforces the need for further studies specifically targeting the cell of interest. To further increase NP internalization, surface modification with natural cationic molecules could be made, but this was not the objective of the work. 

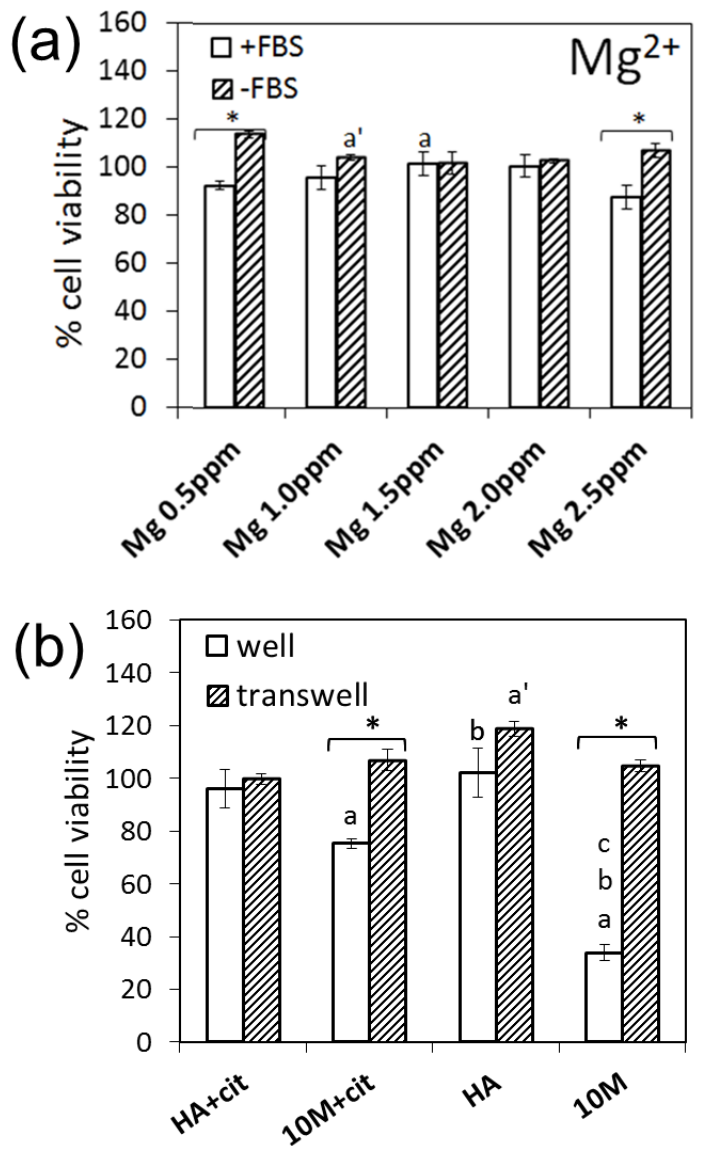

Figure 8 (a) viability of MG63 cells exposed to cell culture media supplemented with various concentrations of $\mathrm{MgCl}_{2}$. (b) Viability of cells exposed directly or indirectly to NPs suspensions in the absence of FBS. "Well" stands for NPs dispersed in the cell culture medium thus in contact with the cells, and "transwell" indicates NPs placed in a transwell to prevent direct contact with the cells while allowing any ionic exchange through the transwell membrane. Letter $a$ and $a^{\prime}$ in graph (a) indicate differences with $0.5 \mathrm{ppm}$ of $\mathrm{MgCl}_{2}$ in the presence or absence of $10 \mathrm{v} / \mathrm{v} \%$ FBS respectively. The * compares significant differences between the same pair of samples cultured with or without $10 \mathrm{v} / \mathrm{v} \%$ FBS. The $a$ and $a^{\prime}$ in graph (b) indicates differences with HA NPs dispersed in citrate; $b$ indicates differences with 10M NPs dispersed in citrate; $c$ indicates differences with HA NPs in the absence of citrate. The * compares significant differences between NPs placed in direct and indirect contact with cells $(P<0.05, N=3)$.

One aspect that we explored but did not succeed in was to "semi-quantitavely" investigate the degree of NP internalization. For this purpose, we performed a series of studies using NPs adsorbed with plasmid encoding green fluorescent protein (DNA-GFP) to compare the degree of NPs internalisation under the different conditions. However, no internalisation was observed even if our TEM studies proved that bare HA and 10M NPs could readily enter into MG63 cells (Fig. 6, 7). We strongly believe that it could have been the adsorption of the DNA-GFP on the NPs surface that rendered a negative charge and prevented their internalisation. This observation suggests that this could occur and thus there is a clear need to develop new strategies that follow internalisation without altering critical parameters such as the surface characteristics of the NPs.

Although seen from the outside, this work might suffer from the innate drawbacks that doping can affect the properties of the nanoparticles including size, surface area, crystallinity and solubility and, in turn, this could negate the effect of ions; it must be borne in mind that not all doping ions caused the same degree of NP modification. In fact, the reason for including 6 different NP formulations was precisely to have the NPs share some common and distinct features to allow comparison. It has been widely reported that characteristics such size, morphology and solubility can affect internalization, but this was not observed. For example, in the series of carbonate-substituted NPs where shape and solubility varied greatly with carbonate content (Figure 2). Instead, HA and $10 M$ NPs share very similar morphological and physicochemical characteristics and exhibited very different cytotoxic behaviour in MG63 cells. Although one could interpret the results and speculate that if both NPs were equally internalized, then $\mathrm{Mg}$ would be the responsible ion for cell cytotoxicity, other explanations might be considered.

The role of $\mathrm{Mg}$ in cancer cells is now better understood [57], and the fact that in cancer cells $\mathrm{Mg}$ channels are overexpressed could explain the more active uptake of $\mathrm{Mg}$ doped NPs. An excess of NPs might then cause their cytotoxicity. Interestingly, additional cell culture studies performed using concentrations as low as $25 \mu \mathrm{g} \mathrm{m}^{-1}$ of NPs have shown cytotoxicity of $10 \mathrm{M}$ NPs. This proves that only a very limited amount is needed to become cytotoxic (see supplementary information).

Although it may be a bit premature, these results suggest that doping is a tool to modify cell behaviour. The simple incorporation of $\mathrm{Mg}$ into $\mathrm{HA}$ could be used to kill cancer cells without the need to conjugate any anticancer drugs onto the NPs. This eliminates all problems associated with drug toxicity.

\section{Cytotoxicity on rMSCs cells}

Besides the potential that doped NPs may have, it is also well known that NP interactions are cell dependent. In this regards, it was very important to test how NPs reacted towards other cell types such as rMSCs. Identical cell culture conditions as those used for MG63 were applied to test the cytotoxicity of the various NPs on rMSCs (Figure 10). Thus, rMSCs were incubated with $100 \mu \mathrm{g} \mathrm{mL}^{-1}$ NPs either as-prepared or well dispersed in cell culture media containing or excluding $10 \mathrm{v} / \mathrm{v} \%$ FBS. The results differ substantially from those observed for MG63 cells. On one hand, it is clear that using bare NPsregardless of whether FBS was added or not-did not compromise cell viability. This changed however, when using NPs dispersed in citrate. In the absence of FBS, viability increased in all doped NPs above $120 \%$ while the non-doped HA-NPs remained at $100 \%$. In the presence of $10 \%$ FBS, we noted an opposite trend: all doped NPs showed $80 \%$ viability while $100 \%$ was maintained for $\mathrm{HA}$. 

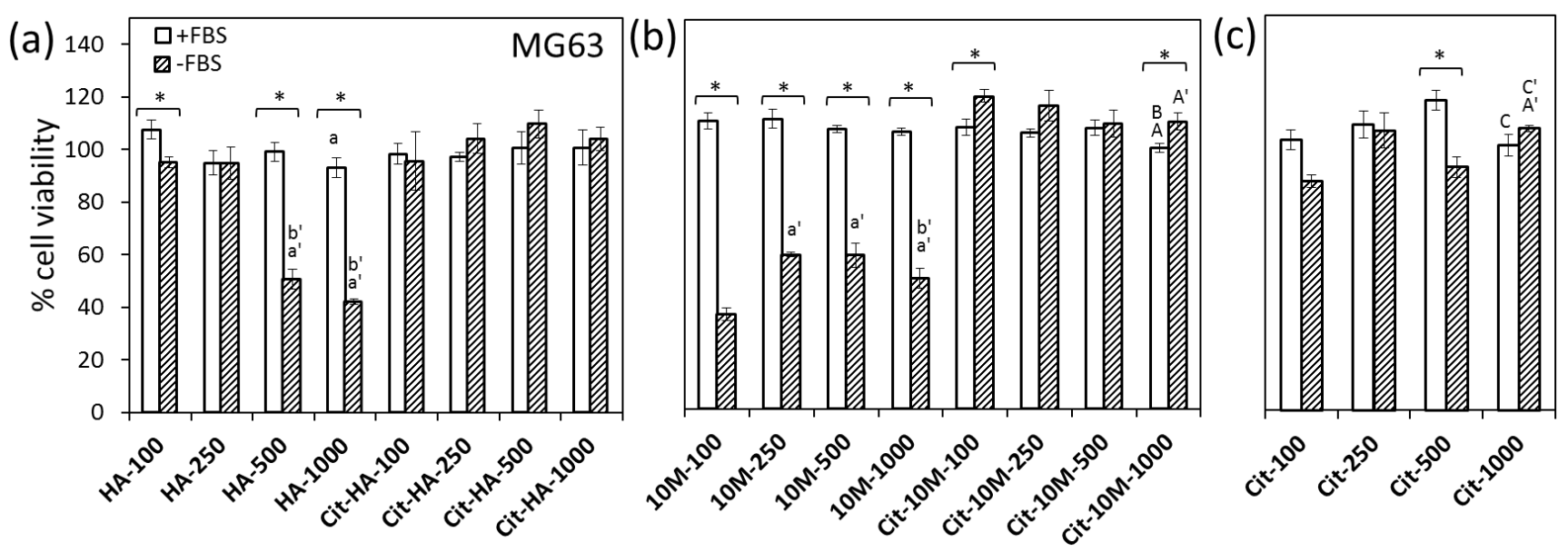

Figure 9 Dose-dependent cytotoxicity of HA (a) and Mg-doped HA (10M) (b) in the presence or absence of $10 \mathrm{v} / \mathrm{v} \%$ FBS. NPs dispersed in citrate and in water (control) were tested. To discard any effect of citrate in the media, cytotoxicity was also performed by supplementing the cell culture media with the same concentration of citrate that was added for the NPs (c). Letters in the graphs indicate significant differences between NPs doses cultured with FBS: a- indicates differences with $100 \mu \mathrm{g} \mathrm{mL}^{-1}$, b- differences with $250 \mu \mathrm{g} \mathrm{mL} \mathrm{L}^{-1}$, c- differences with $500 \mu \mathrm{g} \mathrm{mL}^{-1}$ and, d- differences with $1000 \mu \mathrm{gL}^{-1}$. Letters with (') indicate significant differences between NPs doses cultured without FBS $(P<0.05, N=3)$. Independent analyses were done for the samples containing citrate (capital letters) versus those without citrate (lower case letters). The * compares significant differences between the same pair of NPs cultured with or without $F B S(P<0.05, N=3)$.

Studies performed with increasing NP dose on HA and 10M NPs showed that viability slightly decreased for all cases in a dose dependent manner. This could be an indicator for a higher degree of internalization (Figure 11). In sum (Figure 1011 ), it is interesting to see that unlike MG63 cells, the negative charge that surrounded the NPs upon citrate adsorption did not prevent NPs internalization in rMSCs.

With regards to the effect of the various formulations of doped NPs on rMSCs, there were no significant differences that could be attributed to the presence of the different ions (Figure 10). These findings clearly contrasted with the results obtained for MG63 cells where 10M and 4M7C NPs reacted differently from the rest (Figure 5). Although $\mathrm{Mg}$ and carbonate apparently did not play any major role on rMSCs, this cannot prove that this cell type is not sensitive to NP composition. Other ions might be more critical than the ones selected here. Nevertheless it is worth mentioning that the dose dependent cytotoxicity of HA and 10M formulations did reveal a more pronounced cytotoxic behaviour for HA than for $10 \mathrm{M}$ at higher NPs doses.

This contrasting behaviour of MG63 and rMSCs when treated with NPs has been reported by other authors with similar non-doped HA-NPs. It is not new that HA-NPs can be cytotoxic to cancerous cells but not to normal cells [58]. In fact, the dose dependent assay shown here (Fig. 9) suggests that even the non-doped NPs can become cytotoxic at high NP doses $\left(500 \mu \mathrm{g} \mathrm{mL} \mathrm{L}^{-1}\right.$ ). This anti-tumour activity is generally explained by the higher metabolic activity of cancerous cells versus non-cancerous cells, which causes a higher degree of NP internalization. Moreover, for specific cancerous cells (such as human gastric cancer cells, human cervical adenocarcinoma epithelial cells and human hepatoma cells) higher levels of apoptosis has been shown due to selective NP accumulation in the cell nuclei with no translocation detected in normal cells (e.g. human normal liver cells) [59]. Once in the nuclei, the NPs strongly interact with DNA or DNA-related proteins and disrupt cell functions and trigger apoptosis. However, it is not compulsory for the NPs to enter the nucleus because during cell mitosis the nucleus disassembles and re-forms-this favours NP internalisation.
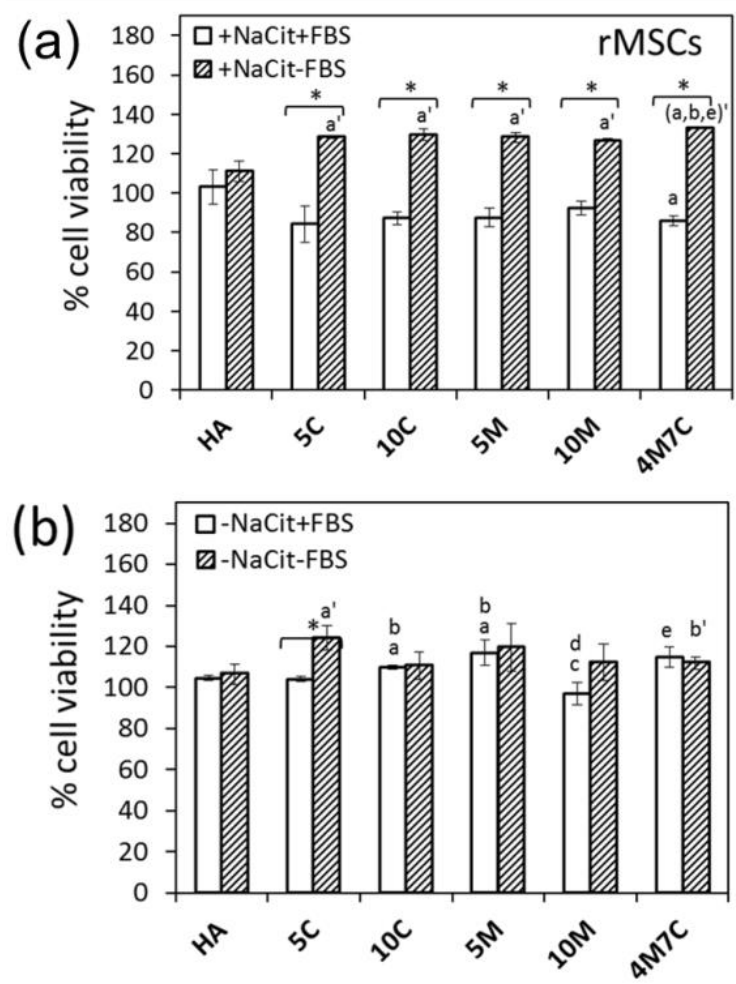

Figure 10 Viability of rMSCs cells exposed to $100 \mathrm{~g} \mathrm{~mL}^{-1}$ of the various NPs for $24 \mathrm{~h}$. (a) Cells exposed to NPs dispersed in citrate in the presence or absence of $10 \mathrm{v} / \mathrm{v} \% \mathrm{FBS}$, and (b) cells exposed to NPs dispersed in water in the presence or absence of $10 \mathrm{v} / \mathrm{v} \%$ FBS. Letters indicate significant differences among 
NPs cultured with FBS: a- indicates differences with HA, bdifferences with $5 \mathrm{C}$, c- differences with $10 \mathrm{C}$, d- differences with $5 \mathrm{M}$ and e- differences with $10 \mathrm{M}$. Letters with (') indicate significant differences among NPs cultured without FBS $(\mathrm{P}<0.05, \mathrm{~N}=3)$. The $*$ indicates significant differences for the same type of NPs cultured with or without FBS $(P<0.05, N=3)$.

Another feature distinguishing the behaviour between cancerous and normal cells was the level of intracellular $\mathrm{Ca}^{2+}$ measured in both cell types upon NPs internalization. The $\mathrm{Ca}^{2+}$ level in cancerous cells was anomalously high but in normal cells the initially high Ca level could soon level off. This explained the preservation of cell viability [54]. Interestingly, while our results support the anti-tumour activity of HA-NPs, we found that this cytotoxicity can further be tuned with NP composition. For MG63, this effect can be greatly enhanced by simply doping the NPs with Mg. In fact, concentrations much lower than the ones reported in the literature are needed to have a cytotoxic effect if using Mg-doped NPs [60]. The most critical aspect is to have the right surface charge to enable NP internalization. In contrast, the rMSCs showed good viability with cytotoxicity only at very high NP doses.

In conclusion, this work addressed the effect of ion doping on HA. We suspect that doped-NPs can be used as drugs by themselves or as carriers of drugs or genes for cell internalization purposes. The results show that ion doping has a significant effect on cells and can trigger specific cell responses, but the results were cell dependent. The fact that a simple action such as doping could be used to selectively kill osteosarcoma cells without compromising the viability of mesenchymal stem cells can provide new means to modulate cell behaviour. Although further studies are needed to understand the mechanism, the 10M-NPs and 4M7C NPs might have great potential in bone cancer treatment.
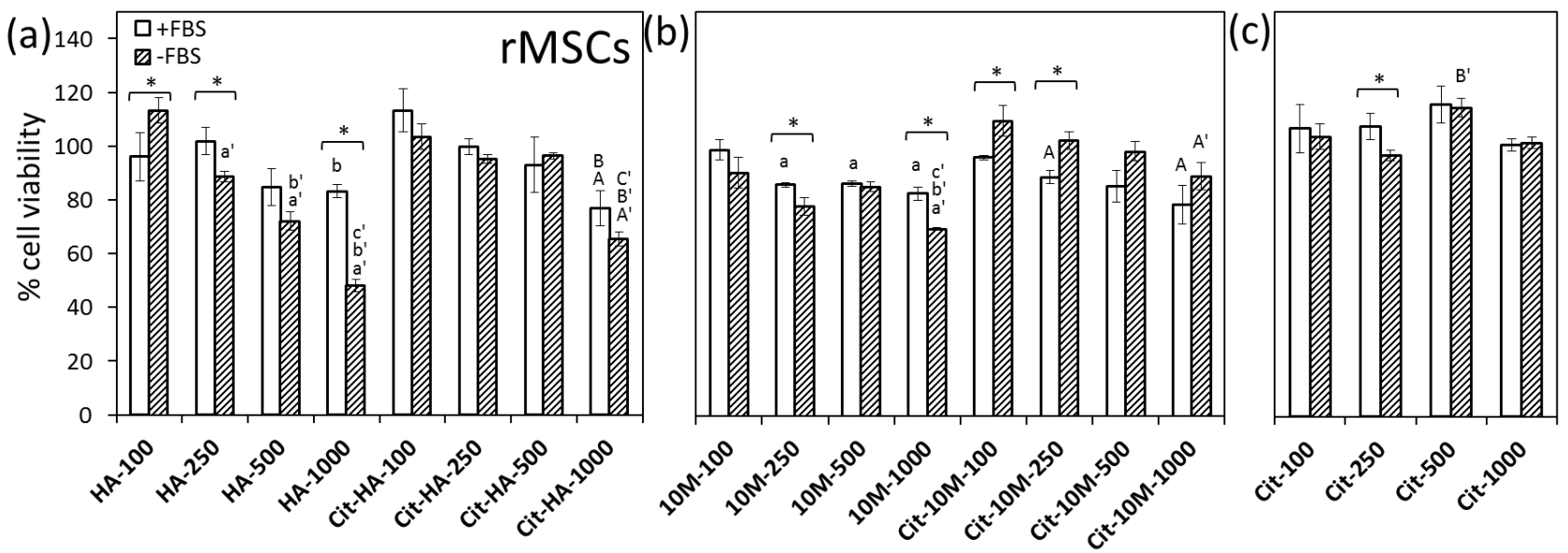

Figure 11 Dose dependent cytotoxicity of HA (a) and Mg-doped HA (10M) (b) in the presence or absence of $10 \mathrm{v} / \mathrm{v} \% \mathrm{FBS}$ on rMSCs. The NPs dispersed in citrate or in water (control) were tested. To discard any effect of citrate in the media, the cytotoxicity was also measured by supplementing the cell culture media with the same concentration of citrate added for the dispersion of the NPs (c). Letters in the graphs indicate significant differences between NPs doses cultured with FBS: a- indicates differences with $100 \mu \mathrm{g} \mathrm{mL}^{-1}$, b- differences with $250 \mu \mathrm{g} \mathrm{mL}^{-1}, \mathrm{c}$ - differences with $500 \mu \mathrm{g} \mathrm{mL}^{-1}$ and, d- differences with $1000 \mu \mathrm{g}$ $\mathrm{mL}^{-1}$. Letters with $\left({ }^{\prime}\right)$ indicate significant differences between NPs doses cultured without $F B S(P<0.05, N=3)$. Independent analyses were done for the samples containing citrate (capital letters) versus those without citrate (lower case letters). The * compares significant differences between the same pair of NPs cultured with or without $F B S(P<0.05, N=3)$. 


\section{Conclusions}

This work proved that ion doping in hydroxyapatite nanoparticles has a strong impact on cell behaviour. From a physicochemical point of view, minute doping caused various changes mainly in the morphology and solubility of the different nanoparticles. However, none of these two characteristics affected cell behaviour. In contrast, the choice of doping ion was critical especially for MG63 cells. Minute amounts of Mg in the NPs ( 1.5 wt\%) led to a marked cytotoxicity in MG63 cells, but not in rMSCs. Although further studies are needed to overcome specific shortcomings, this selectivity seems particularly interesting in the treatment of cancer where simple ion-doping could be exploited in replacement of current toxic drugs.

We also found that NP surface charge affects internalization. Stabilization of a negative surface charge on the surface of the NPs prevents NP internalization in MG63. This behaviour was again cell dependent with lower effects observed in rMSCs. All of these findings are foreseen to have great potential in guiding the design of new NPs with improved biological performance.

\section{Acknowledgements}

Soft X-ray tomography experiments were performed at MISTRAL beamline in the ALBA Synchrotron with the collaboration of ALBA staff. The electron cryomicroscopy unit from the Scientific and Technological Centres of the University of Barcelona is acknowledged for her help with sample preparation and sample transport for soft X-ray imaging. Authors acknowledge the European Commission Seventh Framework Programme for financial support through InnovaBone Project (Grant agreement no. 263363). Funding was also received from the Spanish Government through Project MAT2012-38438-C03, co-funded by the EU through European Regional Development Funds. Support for the research of MPG was received through the "ICREA Academia" award for excellence in research, funded by the Generalitat de Catalunya.

\section{References}

1 E. A. Monroe, W. Votava, D. B. Bass and J. McMullen, J. Dent. Res., 1971, 50, 860-861.

2 K. Fox, P. a Tran and N. Tran, Chemphyschem, 2012, 13, 2495-506.

3 V. Sokolova, O. Rotan, J. Klesing, P. Nalbant, J. Buer, T. Knuschke, A. M. Westendorf and M. Epple, J. Nanoparticle Res., 2012, 14, 910.

4 M. Epple, K. Ganesan, R. Heumann, J. Klesing, A. Kovtun, S. Neumann and V. Sokolova, J. Mater. Chem., 2010, 20, 18.

5 V. Uskoković and D. P. Uskoković, J. Biomed. Mater. Res. B. Appl. Biomater., 2011, 96, 152-91.

6 A. Maitra, Expert Rev. Mol. Diagn., 2005, 5, 893-905.

7 I. Roy, S. Mitra, A. Maitra and S. Mozumdar, Int. J. Pharm., 2003, 250, 25-33.

8 K. Khosravi-Darani, M. R. Mozafari, L. Rashidi and M. Mohammadi, Acta Med. Iran., 2009, 48, 133-41.

9 S.-H. Chu, D.-F. Feng, Y.-B. Ma and Z.-Q. Li, Int. J. Nanomedicine, 2012, 7, 3659-66.

10 B. Palazzo, M. lafisco, M. Laforgia, N. Margiotta, G. Natile, C. L. Bianchi, D. Walsh, S. Mann and N. Roveri, Adv. Funct. Mater., 2007, 17, 2180-2188.

11 X. Cheng and L. Kuhn, Int. J. Nanomedicine, 2007, 2, 667-74.

12 G. Devanand Venkatasubbu, S. Ramasamy, V. Ramakrishnan and J. Kumar, 3 Biotech, 2011, 1, 173-186.

13 G. D. Venkatasubbu, S. Ramasamy, G. P. Reddy and J. Kumar, Biomed. Microdevices, 2013, 15, 711-26.

14 R. Meena, K. K. Kesari, M. Rani and R. Paulraj, J. Nanoparticle Res., 2012, 14, 712.

15 M. lafisco, J. M. Delgado-Lopez, E. M. Varoni, A. Tampieri, L. Rimondini, J. Gomez-Morales and M. Prat, Small, 2013, 9, 3834-44.

16 K. Hasna, S. S. Kumar, M. Komath, M. R. Varma, M. K. Jayaraj 
and K. R. Kumar, Phys. Chem. Chem. Phys., 2013, 15, 810611.

17 S. Panseri, C. Cunha, T. D’Alessandro, M. Sandri, G. Giavaresi, M. Marcacci, C. T. Hung and A. Tampieri, J. Nanobiotechnology, 2012, 10, 32.

18 A. Tampieri, T. D'Alessandro, M. Sandri, S. Sprio, E. Landi, L. Bertinetti, S. Panseri, G. Pepponi, J. Goettlicher, M. BañobreLópez and J. Rivas, Acta Biomater., 2012, 8, 843-51.

19 A. Doat, F. Pellé, N. Gardant and a. Lebugle, J. Solid State Chem., 2004, 177, 1179-1187.

20 E. I. Altinoglu, T. J. Russin, J. M. Kaiser, B. M. Barth, P. C. Eklund, M. Kester and J. H. Adair, ACS Nano, 2008, 2, 20752084.

21 K. H. Müller, M. Motskin, A. J. Philpott, A. F. Routh, C. M. Shanahan, M. J. Duer and J. N. Skepper, Biomaterials, 2013, 35, 1074-1088.

22 Z. Shi, X. Huang, Y. Cai, R. Tang and D. Yang, Acta Biomater., 2009, 5, 338-45.

23 T. Ding, Y. Xue, H. Lu, Z. Huang and J. Sun, IEEE Trans. Nanobioscience, 2012, 11, 336-40.

24 X. Zhao, S. Ng, B. C. Heng, J. Guo, L. Ma, T. T. Y. Tan, K. W. Ng and S. C. J. Loo, Arch. Toxicol., 2013, 87, 1037-52.

25 Y. Cai, Y. Liu, W. Yan, Q. Hu, J. Tao, M. Zhang, Z. Shi and R. Tang, J. Mater. Chem., 2007, 17, 3780.

26 L. Chen, J. M. Mccrate, J. C.-M. Lee and H. Li, Nanotechnology, 2011, 22, 1-20.

27 V. Sokolova, D. Kozlova, T. Knuschke, J. Buer, A. M. Westendorf and M. Epple, Acta Biomater., 2013, 9, 75277535.

28 Z. Xu, C. Liu, J. Wei and J. Sun, J. Appl. Toxicol., 2012, 32, 429-35.

29 F. Qing, Z. Wang, Y. Hong, M. Liu, B. Guo, H. Luo and X. Zhang, J. Mater. Sci. Mater. Med., 2012, 23, 2245-2251.

30 E. Boanini, M. Gazzano and a Bigi, Acta Biomater., 2010, 6 , 1882-94.

31 C. Rey, C. Combes, C. Drouet and M. J. Glimcher, Osteoporos. Int., 2009, 20, 1013-1021.

32 B. Wopenka and J. D. Pasteris, Mater. Sci. Eng. C, 2005, 25, 131-143.

33 J. H. Shepherd, D. V Shepherd and S. M. Best, J. Mater. Sci. Mater. Med., 2012, 23, 2335-47.

34 V. Aina, G. Lusvardi, B. Annaz, I. R. Gibson, F. E. Imrie, G. Malavasi, L. Menabue, G. Cerrato and G. Martra, J. Mater. Sci. Mater. Med., 2012, 23, 2867-79.

35 S. Dasgupta, S. S. Banerjee, A. Bandyopadhyay and S. Bose, Langmuir, 2010, 26, 4958-64.

36 N. Y. Mostafa, H. M. Hassan and O. H. Abd Elkader, J. Am. Ceram. Soc., 2011, 94, 1584-1590.

37 M. S. Sader, K. Lewis, G. a. Soares and R. Z. LeGeros, Mater. Res., 2013, 16, 779-784.

38 C. Capuccini, P. Torricelli, E. Boanini, M. Gazzano, R. Giardino and a Bigi, J. Biomed. Mater. Res. A, 2009, 89, 594-600.

39 S. C. Cox, P. Jamshidi, L. M. Grover and K. K. Mallick, Mater. Sci. Eng. C. Mater. Biol. Appl., 2014, 35, 106-14.

40 Y. Li, C. T. Nam and C. P. Ooi, J. Phys. Conf. Ser., 2009, 187, 012024.

41 E. Landi, A. Tampieri, M. Mattioli-Belmonte, G. Celotti, M. Sandri, A. Gigante, P. Fava and G. Biagini, J. Eur. Ceram. Soc., 2006, 26, 2593-2601. 